\title{
First-episode psychosis and migration in Italy (PEP-Ita migration): a study in the Italian mental health services
}

\author{
Ilaria Tarricone ${ }^{1,2}$, Mauro Braca ${ }^{1 *}$, Fabio Allegri ${ }^{1}$, Giuseppe Barrasso ${ }^{3}$, Antonello Bellomo $^{4}$, Vanna Berlincioni ${ }^{5}$, \\ Bernardo Carpiniello ${ }^{6}$, Alessio Ceregato ${ }^{7}$, Marco Conforti Donati ${ }^{1}$, Samuele Defilippi ${ }^{7}$, Valeria Del Vecchio ${ }^{8}$, \\ Corrado De Rosa ${ }^{8}$, Luigi Ferrannini ${ }^{9}$, Silvia Ferrari ${ }^{10}$, Maria Antonietta Furio ${ }^{12}$, Carla Gramaglia ${ }^{13}$, \\ Caterina La Cascia ${ }^{14,15}$, Mario Luciano ${ }^{8}$, Alice Mulè ${ }^{14,15}$, Marcello Nardini ${ }^{11,12}$, Francesca Podavini ${ }^{5}$, \\ Diego Primavera ${ }^{6}$, Corinna Reggianini ${ }^{10}$, Marco Rigatelli $^{10}$, Orlando Todarello ${ }^{11,12}$, Elena Turella ${ }^{16}$, \\ Antonio Ventriglio ${ }^{4}$, Patrizia Zeppegno ${ }^{13}$, Andrea Fiorillo ${ }^{8}$ and Domenico Berardi ${ }^{1,2}$
}

\begin{abstract}
Background: It has been frequently reported a higher incidence of psychotic disorders in immigrants than in native populations. There is, however, a lack of knowledge about risk factors which may explain this phenomenon. A better understanding of the causes of psychosis among first-generation migrants is highly needed, particularly in Italy, a country with a recent massive migration.

Methods/Design: The "Italian study on first-episode psychosis and migration (PEP-Ita)" is a prospective observational study over a two-year period (1 January 2012-31 December 2013) which will be carried out in 11 Italian mental health centres. All participating centres will collect data about all new cases of migrants with first-episode psychosis. The general purpose ("core") of the PEP-Ita study is to explore the socio-demographic and clinical characteristics, and the pathways to care of a population of first-episode psychosis migrants in Italy. Secondary aims of the study will be: 1) to understand risk and protective factors for the development of psychotic disorders in migrants; 2) to evaluate the correlations between psychopathology of psychotic disorders in migrants and socio-demographic characteristics, migration history, life experiences; 3) to evaluate the clinical and social outcomes of first-episode psychoses in migrants.
\end{abstract}

Discussion: The results of the PEP-Ita study will allow a better understanding of risk factors for psychosis in first-generation migrants in Italy. Moreover, our results will contribute to the development of prevention programmes for psychosis and to the improvement of early intervention treatments for the migrant population in Italy.

Keywords: Migrants, First-episode psychosis, Italy, Risk factors, Protective factors

\section{Background}

Several studies report a higher incidence of psychotic disorders in immigrant populations when compared to native populations [1-4]. Epidemiological studies about the incidence of severe mental disorders in migrants, as well as the identification of specific vulnerabilities and stressors associated with migration, have significantly

\footnotetext{
* Correspondence: mauro.braca@studio.unibo.it

'Department of Medical and Surgical Sciences, Bologna University, Bologna, Italy

Full list of author information is available at the end of the article
}

contributed to the development of models explaining the etiopathogenesis of psychosis in this population. According to the sociodevelopmental model of Morgan et al. [3], the exposure to negative life events can impact on brain development (in particular on the dopaminergic system), as well as on personal sensitivity to stress, inducing a state of persistent vulnerability to psychosis (consisting of social bias, psychotic-like experiences and affective disorders). These factors are thought to weigh on from the perinatal period and through different life stages [5,6]. During childhood, incidents such as head

\section{Biomed Central}


injuries, infectious processes, separation from parents, lack of social relationships, psychological, physical or sexual abuse and bullying are likely to be associated with the development of psychosis [7-9]. During adolescence, cannabis abuse is considered an 'at risk' behavior, along with other subjective experiences, such as discrimination and bullying at school, which appear to increase the individual risk of developing psychotic disorders $[10,11]$. In adulthood, relevant factors that seem to be associated with the onset of psychosis are social exclusion, racial discrimination, discrepancy between expectations and achievements, lack of confidants/emotional relationships, and loneliness $[12,13]$.

Risk factors for the development of psychosis are not only at an individual level, but also in the social area [14]. It has been shown that the risk of developing psychosis is higher in urban areas [15-17], but the meaning of this association remains unclear; it is assumed that one reason could be social isolation which occurs in large urban areas $[18,19]$. In addition, other factors, such as exposure to pollutants, lifestyle, capacity/ability to relate to environment, and restricted working environments, may represent other risk factors. Indeed, the quality and the resources of the social structure in which a person lives (the so-called "social capital") may also significantly affect their risk of developing psychosis [20]. Some studies have shed light on how urban areas which are characterized by the presence of strong socio-economic disparities show a higher incidence of psychosis [21].

The migratory process is a life experience that puts the individual at an increased risk of dealing with the events and factors listed above [22]. In fact, the events experienced by migrants with psychotic onset may be considered a negative life event itself. A better understanding of this process may constitute the key to explain the higher risk of psychosis in these patients.

The high incidence of psychosis in migrants has been described by Morgan [23] as 'a tragedy of public health'. Moreover, it has been reported that access to mental health care for migrants can be particularly difficult, notwithstanding the high psychiatric morbidity that exists in this population [24-26].

Only few studies have investigated the risk factors for the onset of psychotic disorders in migrants in Italy $[4,27]$. Here health care is provided to the population by the Italian National Health Service, which is built like the British National Health Service. All the population has unlimited health care coverage, which is provided by "Local Health Units", each responsible for a geographically defined catchment area. Access to health services is generally free of charge. Accordingly with the 1978 reform, psychiatric care is delivered by general hospital psychiatric wards for acute admissions, and community mental health centres $(\mathrm{CMHC})$ providing psychiatric care to geographically defined areas. Non-resident people such as temporary migrants can access to care as much as resident population for urgent and/or necessary cases. CMHCs (an average of 1.81 services per 150,000 population) deliver individual consultations and domiciliary care activities, keep contacts with other health and social agencies and provide emergency interventions. They have a multidisciplinary staff, including psychiatrists, psychologists, social workers, nurses, and educators. Migrants are cared by the same CMHCs of the general population, and cultural-competent activities are provided on demand (e.g. interpreters, cultural mediators, social/legal support, etc.) $[28,29]$. So structured, such an organization would facilitate access to care for migrants presenting first-episode psychosis in Italy; yet, previous studies demonstrated that migrants with mental disorders might follow different and more complex pathways to care [26].

Migration to Italy is a relatively recent phenomenon, mainly developed in the last 20 years and still increasing $(+8.2 \%$ in 2013) [30]. At the beginning of 2013, migrants represented $7.4 \%$ of the resident population. Migrants come to Italy from any continent, more frequently from European countries (both EU, 27.4\% and non-EU, 23.4\%); $22.1 \%$ from Africa, followed by Asian (18.8\%) and American (8.3\%) migrants. The most represented countries of origin are Romania (21.2\%), Albania (10.6\%), Morocco (9.9\%), China (4.6\%), Ukraine (4.4\%), Philippines (2.9\%), Moldova (2.9\%), India (2.6\%), Poland $(2.4 \%)$ and Tunisia (2.3\%) [31]. Most migrants in Italy live in the Northern regions $(61.8 \%)$ and emigrated to find a job, though the reason for migration has suddenly changed in the recent years: in 2012, family reasons (81.322 migrants) became more frequent than work reasons $(52.328 \mathrm{mi}-$ grants), probably because of the progressive decrease of job offer in Italy and the stagnation in labour market [30]. Also, migrants who come to Italy are frequently asylum-seekers: in 2012 about 60.000 people have reached our coasts from Tunisia and Lybia.

Based on these premises, this research project was promoted in order to understand risk factors for psychosis in migrants, which could be targeted by specific psychosocial interventions.

The study will be carried out by 11 study centres across Italy and will be coordinated by the Bologna Transcultural Psychiatric Team (BoTPT) [27,32-34]. The BoTPT is a team of the University of Bologna, which works closely with the Bologna Department of Mental Health and Pathological Addictions in its provision of cultural-competent treatment care of mental disorders. It also performs consultation and liaison interventions for other urban services that deal with social and health problems of migrants and their families, such as local social services and voluntary organizations. The BoTPT also 
collaborates with other psychiatric services and University departments in Italy on the topic of migration and mental health. These collaborations are performed in order to understand the occurrence of different disorders in relation to specific cultural contexts, the different migratory movements in different areas, as well as the specific models of care. An initial investigation involving four Italian centres revealed important differences in pathways to care and the socio-demographic characteristics of migrants attending psychiatric services [26].

More recently, Bologna has become part of the EU-GEI European project (European Community's Seventh Framework Program, grant agreement No. HEALTH-F22009-241909, Project EU-GEI: European Network of National Schizophrenia Networks Studying GeneEnvironment Interaction) coordinated by the University of Maastricht. Bologna's participation in EU-GEI and the Work Package 2 (coordinated by Craig Morgan and Robin Murray from the Institute of Psychiatry King's College, London) allowed the use of EU-GEI's methods both in Bologna and in the independent network of Italian mental health centres which are taking part to the Italian study on first-episode psychosis and migration (PEP-Ita migration study).

The Italian study on first-episode psychosis and migration (PEP-Ita) brings together spontaneous and independent research experiences in various Italian mental health centres (psychiatric wards, psychiatric consultation-liaison services and/or CMHCs) with the purpose to study the incidence of psychosis in migrants in Italy. The general aim ("core") of the study is to explore the socio-demographic and clinical characteristics, and the pathways to care of a population of first-episode psychosis (FEP) migrants in Italy. The study has the following secondary aims: 1) to understand risk and protective factors for the development of psychotic disorders in migrants; 2) to evaluate the link between psychopathology of psychotic disorders in migrants and socio-demographic characteristics, migration history, life experiences; 3 ) to assess the clinical and social outcome of FEP in migrants.

\section{Methods}

\section{Study design}

The PEP-Ita migration project is a prospective observational study over a two-year period (1 January 2012-31 December 2013). All mental health centres participating in the study (Table 1) will collect data on all new cases of migrants with first-episode psychosis and, if their catchment areas will allow it, they will evaluate the incidence of psychosis in migrants. Data collection will be carried out through a central computerized system.

Based on data from the Italian National Institute of Statistics (ISTAT) [35], with a whole catchments area of

Table 1 Italian study on first-episode psychosis and migration (PEP-Ita migration) - Mental Health Centres network

\begin{tabular}{|c|c|}
\hline Study centers & Mental Health Services and Universities \\
\hline \multicolumn{2}{|r|}{ Coordinating centres } \\
\hline \multirow[t]{2}{*}{ Bologna } & - Bologna Transcultural Psychiatric Team (BoTPT) - Department of Medical and Surgical Sciences, University of Bologna \\
\hline & - Department of Mental Health and Pathological Addictions, Local Health Trust, Bologna \\
\hline Napoli & - Department of Psychiatry, University of Naples SUN \\
\hline \multicolumn{2}{|r|}{ Participant centres } \\
\hline Andria* & - Andria Community Mental Health Centre \\
\hline \multirow[t]{2}{*}{ Bari* } & - U.O. di Psichiatria - Azienda Ospedaliero Universitaria "Consorziale Policlinico" Bari \\
\hline & - Dipartimento di Scienze Mediche di Base, Neuroscienze ed Organi di Senso, Università degli Studi Aldo Moro di Bari \\
\hline \multirow[t]{2}{*}{ Bologna } & - Department of Medical and Surgical Sciences, University of Bologna \\
\hline & - Department of Mental Health, Ausl Bologna \\
\hline Cagliari* & - Clinica Psichiatrica - Università degli Studi di Cagliari \\
\hline Camposampiero (PD) & - U.O.A. di Psichiatria di Camposampiero (PD) \\
\hline Chivasso (TO) & - Department of Mental Health A.S.L. TO4 \\
\hline Foggia & - Department of Clinical and Experimental Sciences, Section of Psychiatry and Clinical Psychology, University of Foggia \\
\hline Modena & - U.O. Psichiatria Ospedaliero-Universitaria Modena Centro, University of Modena and Reggio Emilia \\
\hline Novara & $\begin{array}{l}\text { SC Psichiatria, AOU Ospedale Maggiore della Carità, Dipartimento di Medicina Traslazionale, Università del } \\
\text { Piemonte Orientale Amedeo Avogadro, Novara, Italy }\end{array}$ \\
\hline \multirow[t]{2}{*}{ Palermo } & - Psychiatric Unit, Azienda Ospedaliera Universitaria Policlinico "P. Giaccone" Palermo \\
\hline & - Department of Experimental Biomedicine and Clinical Neuroscience, Section of Psychiatry, University of Palermo \\
\hline Pavia & - Department of Brain and Behavioral Sciences, University of Pavia \\
\hline
\end{tabular}

*Research protocol currently under approval. 
2.135.145 inhabitants and 6.5\% of migrants, and considering a conservative estimate of yearly incidence cases of 20/100.000 among Italians and 40/100.000 among migrants, as already reported by previous estimates [4], we will expect to recruit 111 FEP migrants cases by year 2 . Twenty-four months after the survey period, we will conduct a leakage study to identify any subject that may have been missed during the critical data collection period. In order to do so, we will review all new mental health service registration forms and will interrogate the computerized information systems.

Besides the main study design, optional levels (Figure 1) of the research are: 1) an in-depth assessment of FEP migrant patients through the administration of a battery of research instruments (listed below); 2) a case-control study, the control group consisting in FEP native patients consecutively attending psychiatric services in the same catchment areas and in the same study period as FEP migrant patients; 3) a follow-up study, which will perform a threeand a twelve-months follow-up assessment.

\section{Study population}

The study will include untreated first-generation migrants with FEP who seek treatment for the first time at participating mental health centres during the recruitment period. As the World Health Organization, we define "migrants" people who move from one area to another for varying periods of time and reasons [36]; specifically, with "first-generation migrants" we mean people who were born in a foreign country and have moved to Italy for any period or reason: thus we refer to international migrants and not to internal ones. In order to ensure that patients have not yet presented and been treated for a psychotic episode, an accurate medical history will be recorded together with patients and, where necessary, with their families. Previous use of medications or other therapeutic strategies will be the object of a strict survey.

The inclusion criteria for the study population are: 1) diagnosis of a psychotic episode, defined on the basis of the criteria currently in use (Diagnostic and Statistical Manual of Mental Disorders - DSM-IV-TR) [37]; 2) age between 18 and $64 ; 3$ ) patients living in the study area of the involved mental health centres; 4) patients who accept to participate in the study and sign a valid informed consent. Patients will be excluded in case of comorbid mental retardation, moderate or severe, based on the criteria in current use (Diagnostic and Statistical Manual of Mental Disorders - DSM-IV-TR) [37]. Patients will be assessed by the WAIS-III short form [38]. The inclusion criteria for control native patients are the same as migrants: thus, all native patients consecutively presenting a first-episode psychosis and admitted to the designated psychiatric services for each study centre in the recruitment period (1 January 2012-31 December 2013) will be recruited as controls. Because of these recruitment criteria, control native patients will not be matched to migrant patients, and we will not be able to predict the number of controls until the recruitment process is concluded.

\section{Assessment}

For each patient, the following information will be collected: 1. Informed consent; 2. Socio-demographic data (gender, birth date and place, ethnicity, marital status, educational level, employment status, housing status). As regards the optional levels of study, the evaluations will be performed by the use of a wide series of tests derived from the EU-GEI protocol [39] and by other research experiences of the participating centres.

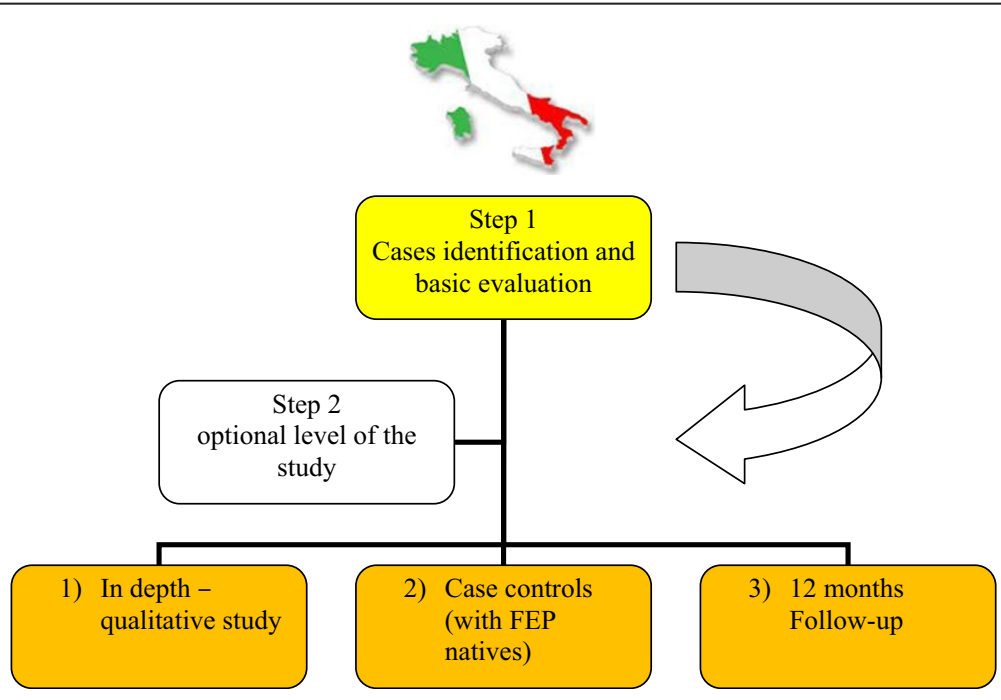

Figure 1 Study design. 
1. Nottingham Onset Schedule: Duration of Untreated Psychosis version (NOS-DUP) [40] to examine the duration of untreated psychosis;

2. Bologna Pathway to Care Scale (BPCS) to provide information on routes of access to mental health care (general practitioners, patients' direct access, family members' involvement, other psychiatric services, etc.).

3. Bologna Migration History Questionnaire and Social Integration Interview (BO-MHQ) [4] for the study of the history of migration and the experiences related to it;

4. Association for Methodology and Documentation in Psychiatry (AMDP) [41] and Operational Criteria Checklist (OPCRIT) [42,43] for a thorough psychopathological rating;

5. Premorbid Adjustment Scale (PAS) [44] to evaluate the premorbid adjustment;

6. Childhood Experiences of Care and Abuse Questionnaire (CECA-Q) [45] and Childhood Trauma Questionnaire (CTQ) [46] to assess the presence of childhood trauma in the history of the patient;

7. Amended Bullying Questionnaire [47] to assess acts of bullying by peers (emotional, psychological or physical violence) inflicted on the subject before the age of 17;

8. Harvard Trauma Questionnaire (HTQ) [48] to investigate traumatic experiences that occurred during adult life;

9. The Built Environment Assessment Tool (BEAT) [49] allows the classification of the area of residence of the subject on the basis of a set of architectural evaluation criteria and available infrastructure.

10. Discrimination Questionnaire [50], a modified 12 -item scale for significant and everyday elements of interpersonal discrimination;

11. Cannabis Experiences Questionnaire (CEQ) [51] to investigate the intake of cannabis and the subjective experience which results;

12. Brief Core Schema Scales (BCSS) [52] for the evaluation of positive and negative perceptions of self and others;

13. Community Assessment of Psychic Experience (CAPE) [53] to assess the schizotropical vulnerability;

14. Devaluation of Consumers Families Scale (DCFS) and Devaluation of Consumers Scale (DCS) [54] to measure the stigma perceived by service users and their families;

15. Schedules for Clinical Assessment in Neuropsychiatry (SCAN) [55] to obtain a standardized diagnosis and assess the psychopathology in detail;
16. Global Assessment of Functioning Scale (GAF) [35], Axis V of the DSM-IV, and Schedule for the Deficit Syndrome (SDS) [56] for the evaluation of the overall operation;

17. Medical lists: list of drugs taken at the time of evaluation.

Assessments will be carried out by psychiatrists or clinical psychologists appropriately trained in the use of the above-mentioned assessment instruments. The full assessment takes approximately 3 hours and it will be conducted within 2 to 4 sessions. In case of relevant linguistic barriers, a cultural mediator will join the clinical researcher: however, research questionnaires have been translated into several languages (English, French, German, Dutch, Spanish, Portuguese, Turkish, Serbian) through a back-translation process. This will help the direct assessment of the patient, confining the presence of cultural mediators only to those cases where migrants have significant linguistic barriers and instruments in their own language are not available. The level of agreement among professionals will be assessed after training on simulated cases through Cohen's kappa coefficient.

\section{Online database}

Data will be entered into a computerized database, which will be accessible online by all centres participating in the study. The computerized system will have the following characteristics: 1) usability: the proposed software is characterized by immediacy and effectiveness in data entering and management; 2) compatibility: the system ensures optimal use by the most popular browsers, such as Internet Explorer and Mozilla Firefox; 3) multicentric management: the system will be accessible from different centres with diversified access codes; 4) users' management: the application will enable use from authorized users according to their profile. There will be two types of profile: user profiles and admin profiles. The former profile will be used to perform simple data entries, while the admin profile will have full access to the details of the system and advanced features; 5) advanced functions: control of entered data with ability to view the main summary information and export to CSV/ EXCEL format for subsequent statistical studies. These functions enable a constant monitoring of the work evolution by centralizing data and enabling real-time and accurate assessment of the study course, solicitation of the participants, and correction of possible errors.

\section{Ethical considerations}

After a full explanation of the nature of the study, subjects will be asked to participate in the study, and if they accept, they will be asked to sign the informed consent form. Subjects will be ensured that all data remain 
anonymous. Intelligence about the participation of the patient will not be included in their medical record. Identification codes will be assigned to each subject in order to protect their confidentiality and ensure all data remain anonymous. The subjects may withdraw from the study at any time. The study protocol has been approved by the ethics committee of the coordinating Centre (Bologna) and has been submitted to each local ethics committee (Table 1).

\section{Commercial and patent rights - dissemination of results} Patients' rights, and other forms of economic utilization of research results, are considered indisputable rights of the study. It is also considered right of the study to use the data acquired in seminars, conferences, and scientific publications.

\section{Expected side effects and possible contraindications}

There are no predictable side effects that can be attributed to the participation in this study. Patients will continue to receive their usual therapies, and any adverse events that occur during the administration of therapeutic procedures will be notified to the authorities in accordance with the applicable laws.

\section{Ethical evaluation}

The research study described does not present any particular ethical problems.

\section{Discussion}

\section{Expected results and clinical implications}

The study will gather relevant information on the sociodemographic and clinical features, and pathways to care of migrants with first-episode psychosis in Italy. The comparison with native patients will highlight specific risk factors for psychosis in migrants. As a future perspective, it would be an interesting additional research field a case-control study with migrants who, having been recruited in the same catchment areas at the same period of data collection, have not developed psychosis. Finally, the inclusion of mental health centres located in different social and geographic areas will allow interregional comparisons of risk factors for psychosis in migrants. Selected centres will be able to obtain more indepth information on both individual and area-specific social risk factors, as well as an evaluation of the family burden of patients with a psychotic onset. We expect that the results of this study will contribute to the development of prevention programs for psychosis in migrants and will help to improve the effectiveness of early intervention treatments within migrant population.

\section{Competing interests}

The authors declare that they have no competing interests.

\section{Authors' contributions}

IT is the network main coordinator, the main study-designer and manuscript writer. AF is a network co-coordinator and has significantly collaborated to the study design and the manuscript draft. $\mathrm{MB}$ is a network co-coordinator and has collaborated to the data collection and the manuscript draft. VB, BC, $L F, M N, M R, O T, P Z$ and $D B$ are responsible for the coordination of recruitment and assessment in the local centres, they have also advised on the development of the design and have given the final approval of this version to be published. FA, GB, AB, AC, SD, VDV, CDR, SF, MAF, CG, CLC, ML, AM, FP, $D P, C R$, ET and $A V$ are responsible for the recruitment, the clinical assessment and the manuscript revision. MCD is our Information Technology Supervisor, he has created the online database and will perform statistical analyses. All authors read and approved the final manuscript.

\section{Acknowledgements}

We acknowledge the contribution of Dr. Craig Morgan and Prof. Robin Murray, leaders of the Working Package 2 of the EU-GEI Project funded by the European Community (European Network of National Schizophrenia Networks Studying Gene Environment Interactions Project EU-GEI European Community's Seventh Framework Program, grant agreement No. HEALTH-F22009-241909). WP2 allowed us to implement the EU-GEl research tools in the present project. We also deeply thank Dr. Marta Di Forti: her help was crucial in developing PEP-Ita Migration network. A special thanks goes to Prof. Dinesh Bhugra and to Dr. Jane Boydell for their suggestions on methodology and research strategy in cultural psychiatry and psychiatric epidemiology. We thank Dr Angelo Fioritti (Director of Bologna Mental Health Department) and Dr Antonella Piazza (Responsible of Bologna MHD computer Information System). We also acknowledge the contribution of the following study centres to the Pep-Ita network: CPS zona 14 e Rozzano - SPDC Est AO San Paolo Milano (Dr. Angelo Bertani), Università Cattolica del Sacro Cuore Roma (Dr. Emanuele Caroppo), Carcere di Regina Coeli Roma (Dr. Paolo Cianconi), Università degli Studi di Udine (Prof. Matteo Balestrieri), Università degli Studi dell'Insubria Varese-Como (Prof. Simone Vender). A special and deep thanks to Professor Rocco Pollice who, together with Andrea Fiorillo, Alice Mulè and Ilaria Tarricone, took the first step of this project one morning, several years ago, in Naples.

\section{Author details}

${ }^{1}$ Department of Medical and Surgical Sciences, Bologna University, Bologna, Italy. ${ }^{2}$ Department of Mental Health and Pathological Addictions, Local Health Trust, Bologna, Italy. ${ }^{3}$ Andria Community Mental Health Centre, Andria, BAT, Italy. ${ }^{4}$ Department of Clinical and Experimental Sciences, Section of Psychiatry and Clinical Psychology, University of Foggia, Foggia, Italy. ${ }^{5}$ Department of Brain and Behavioral Sciences, University of Pavia, Pavia, Italy. ${ }^{6}$ Clinica Psichiatrica - Università degli Studi di Cagliari, Cagliari, Italy. ${ }^{7}$ Mental Health Department A.S.L. TO4, Chivasso, TO, Italy. ${ }^{8}$ Department of Psychiatry, University of Naples SUN, Napoli, Italy. ${ }^{9}$ Department of Mental Health ASL 3 Liguria, Genova, Italy. ${ }^{10}$ U.O. Psichiatria Ospedaliero-Universitaria Modena Centro, University of Modena and Reggio Emilia, Modena, Italy. ${ }^{11}$ U.O. di Psichiatria - Azienda Ospedaliero Universitaria "Consorziale Policlinico" Bari, Bari, Italy. ${ }^{12}$ Dipartimento di Scienze Mediche di Base, Neuroscienze ed Organi di Senso, Università degli Studi Aldo Moro di Bari, Bari, Italy. ${ }^{13} \mathrm{SC}$ Psichiatria, AOU Ospedale Maggiore della Carità, Dipartimento di Medicina Traslazionale, Università del Piemonte Orientale Amedeo Avogadro, Novara, Italy. ${ }^{14}$ Psychiatric Unit, Azienda Ospedaliera Universitaria Policlinico "P. Giaccone" Palermo, Palermo, Italy. ${ }^{15}$ Department of Experimental Biomedicine and Clinical Neuroscience, Section of Psychiatry, University of Palermo, Palermo, Italy. ${ }^{16}$ U.O.A. di Psichiatria di Camposampiero (PD), Camposampiero, PD, Italy.

Received: 8 August 2013 Accepted: 28 May 2014

Published: 23 June 2014

\section{References}

1. Harrison G, Glazebrook C, Brewin J, Cantwell R, Dalkin T, Fox R, Jones P, Medley I: Increased incidence of psychotic disorders in migrants from the Caribbean to the United Kingdom. Psychol Med 1997, 27:799-806.

2. Cantor-Graae E, Selten JP: Schizophrenia and migration: a meta-analysis and review. Am J Psychiatry 2005, 162:12-24. 
3. Morgan C, Charalambides M, Hutchinson G, Murray RM: Migration, ethnicity, and psychosis: toward a sociodevelopmental model. Schizophr Bull 2010, 36:655-664.

4. Tarricone I, Mimmi S, Paparelli A, Rossi E, Mori E, Panigada S, Carchia G, Bandieri V, Michetti R, Minenna G, Boydell J, Morgan C, Berardi D: First-episode psychosis at the West Bologna Community Mental Health Center: results of an 8-year prospective study. Psychol Med 2012, 42:2255-2264

5. Boydell J, Van Os J, McKenzie K, Allardyce J, Goel R, McCreadie RG, Murray RM: Incidence of schizophrenia in ethnic minorities in London: ecological study into interactions with environment. BMJ 2001, 323:1336-1338.

6. Mäki P, Veijola J, Jones PB, Murray GK, Koponen H, Tienari P, Miettunen J, Tanskanen P, Wahlberg KE, Koskinen J, Lauronen E, Isohanni M: Predictors of schizophrenia-a review. Br Med Bull 2005, 9:1-15.

7. Wilcox JA, Nasrallah HA: Childhood head trauma and psychosis. Psychiatry Res 1987, 21:303-306

8. David AS, Prince M: Psychosis following head injury: a critical review. J Neurol Neurosurg Psychiatry 2005, 76:53-60

9. Dalman C, Allebeck P, Gunnell D, Harrison G, Kristensson K, Lewis G, Lofving S, Rasmussen F, Wicks S, Karlsson H: Infections in the CNS during childhood and the risk of subsequent psychotic illness: a cohort study of more than one million Swedish subjects. Am J Psychiatry 2008, 165:59-65.

10. Semple DM, McIntosh AM, Lawrie SM: Cannabis as a risk factor for psychosis: systematic review. J Psychopharmacol 2005, 19:187-194

11. Large M, Sharma S, Compton MT, Siade T, Nielssen O: Cannabis use and earlier onset of psychosis: a systematic meta-analysis. Arch Gen Psychiatry 2011, 68:555-561.

12. Harrison $G$, Eaton $W$ : Migration and the social epidemiology of schizophrenia. In Risk and Protective Factors in Schizophrenia. Towards a conceptual Model of Disease Process. Edited by Hafner H. Darmstadt: Steinkopff Verlag; 2002:113-122.

13. Van Os J, Janssen I, Hanssen M, Bak M, Myin-Germeys I, Marcelis M, Bijl R, Vollebergh W, Delespaul P: Cognitive Epidemiology: Psychological and Social Risk Mechanisms for Psychosis. In Risk and Protective Factors in Schizophrenia. Towards a Conceptual Model of the Disease Process. Edited by Hafner H. Darmstadt: Steinkopff Verlag; 2002:39-57.

14. Heinz A, Deserno L, Reininghaus U: Urbanicity, social adversity and psychosis. World Psychiatry 2013, 12:187-197.

15. Lewis G, David A, Andréasson S, Allebeck P: Schizophrenia and city life. Lancet 1992, 340:137-140.

16. Mortensen PB, Pedersen CB, Westergaard T, Wohlfahrt J, Ewald H, Mors O, Andersen PK, Melbye M: Effects of family history and place and season of birth on the risk of schizophrenia. N Engl J Med 1999, 340:603-608.

17. Krabbendam L, Myin-Germeys I, Bak M, Van Os J: Explaining transitions over the hypothesized psychosis continuum. Aust N Z J Psychiatry 2005, 39:180-186.

18. Van Os J, Hanssen M, Bijl RV, Vollebergh W: Prevalence of psychotic disorder and community level of psychotic symptoms: an urban-rural comparison. Arch Gen Psychiatry 2001, 58:663-668.

19. De Rosa C, Luciano M, Del Vecchio V, Sampogna G, Del Gaudio L, Fizzotti C, Palumbo C, Atti AR, Di lorio G, Pinna F, Signorelli MS, Gotelli S, La Ferla T, Piselli M, De Fazio P, Bardicchia F, Fantini E, Spattini L, Ginanneschi A, Piras S, Mulè A, Ciafone M, Cava L, Tarsitani L, Botter V, Bertossi F, Macina A, Carrà G, Catapano F, Fiorillo A: Urban insecurity and fear of crime in people suffering from patients with mental disorders: preliminary results of a multicentric Italian study. Riv Psichiatr 2013, 48:321-327.

20. Kirkbride JB, Jones PB: The prevention of schizophrenia - what can we learn from eco-epidemiology? Schizophr Bull 2011, 37:262-271.

21. Mueser KT, McGurk SR: Schizophrenia. Lancet 2004, 363:2063-2072.

22. Bhugra D, Jones P: Migration and mental illness. Adv Psychiatr Treat 2001, 7:216-223

23. Morgan C, Hutchinson G: The social determinants of psychosis in migrant and ethnic minority population: a public health tragedy. Psychol Med 2009, 1:1-5

24. Bhui $\mathrm{K}$ : The language of compliance: health policy and clinical practice for the severely mentally ill. Int I Soc Psychiatry 1997, 43:157-163.

25. Bhui K, Bhugra D: Explanatory models for mental distress: implications for clinical practice and research. Br J Psychiatry 2002, 181:6-7.

26. Tarricone I, Stivanello E, Ferrari S, Colombini N, Bolla E, Braca M, Giubbarelli C, Costantini C, Cazzamalli S, Mimmi S, Tedesco D, Menchetti M, Rigatelli M,
Maso E, Balestrieri M, Vender S, Berardi D: Migrant pathways to community mental health centers in Italy. Int I Soc Psychiatry 2012, 58:505-511.

27. Tarricone I, Atti AR, Salvatori F, Braca M, Ferrari S, Malmusi D, Berardi D: Psychotic symptoms and general health in a socially disadvantaged migrant community in Bologna. Int I Soc Psychiatry 2009, 55:203-213.

28. De Girolamo G, Cozza M: The Italian Psychiatric Reform. A 20-year perspective. Int J Law Psychiatry 2000, 23:197-214.

29. Volpe U, Fiorillo A, Luciano M, Del Vecchio V, Palumbo C, Calò S, Piras S, Signorelli M, Filippo D, Piselli M, De Fazio P, Gotelli S, Bardicchia F, Cerveri G, Ferrari S, Mulè A, Ribolsi M, Sampogna G, De Rosa C, Sartorius N: Pathways to mental health care in Italy: results from a multicenter study. Int I Soc Psychiatry 2013. [Epub ahead of print] DOI: 0020764013501648.

30. Ufficio Nazionale Antidiscriminazioni Razziali (UNAR): Immigrazione - Dossier Statistico 2013. Rome: Dalle discriminazioni ai diritti: Rapporto UNAR; 2013.

31. Caritas-Migrantes: Dossier Statistico Immigrazione. Rome: $22^{\circ}$ Rapporto; 1999.

32. Tarricone I, Atti AR, Braca M, Pompei G, Morri M, Poggi F, Melega S, Stivanello E, Tonti L, Nolet M, Berardi D: Migrants referring to the Bologna Transcultural Psychiatric Team: reasons for drop-out. Int I Soc Psychiatry 2011, 57:627-630.

33. Tarricone I, Stivanello E, Poggi F, Castorini V, Marseglia MV, Fantini MP, Berardi D: Ethnic variation in the prevalence of depression and anxiety in primary care: a systematic review and meta-analysis. Psychiatry Res 2012, 195(3):91-106

34. Braca M, Berardi D, Mencacci E, Belvederi Murri M, Mimmi S, Allegri F, Mazzi F, Menchetti M, Tarricone I: Understanding psychopathology in migrants: a mixed categorical-dimensional approach. Int I Soc Psychiatry 2014, 60(3):243-253.

35. ISTAT - The Italian National Institute of Statistics. [http://demo.istat.it/]

36. World Health Organization (WHO): International Migration, Health and Human Rights (Health \& Human Rights Publication Series - Issue n.4). Geneva: World Health Organization; 2003.

37. American Psychiatric Association: Diagnostic and Statistical Manual of Mental Disorders (4th ed., Text Revision). Washington, DC: Author; 2000

38. Ringe WK, Saine KC, Lacritz LH, Hynan LS, Cullum CM: Dyadic short forms of the Wechsler Adult Intelligence Scale-III. Assessment 2002, 9:254-260.

39. European Network of Schizophrenia Networks for the Study of GeneEnvironment Interactions: Schizophrenia aetiology: do gene-environment interactions hold the key? Schizophr Res 2008, 102:21-26.

40. Singh SP, Cooper JE, Fisher HL, Tarrant CJ, Lloyd T, Banjo J, Corfe S, Jones P: Determining the chronology and components of psychosis onset: the Nottingham Onset Schedule (NOS). Schizophr Res 2005, 80:117-130.

41. Conti L, Dell'Osso L, Cassano GB: II sistema AMDP. Manuale per la valutazione e la documentazione della psicopatologia. Milano: Edizioni Grafiche Mazzucchelli; 1990.

42. McGuffin P, Farmer A, Harvey I: A polydiagnostic application of operational criteria in studies of psychotic illness. Development and reliability of the OPCRIT system. Arch Gen Psychiatry 1991, 48:764-770.

43. Craddock M, Asherson P, Owen MJ, Williams J, McGuffin P, Farmer AE: Concurrent validity of the OPCRIT diagnostic system. Comparison of OPCRIT diagnoses with consensus best-estimate lifetime diagnoses. $\mathrm{Br} J$ Psychiatry 1996, 169:58-63.

44. Cannon-Spoor HE, Potkin SG, Wyatt RJ: Measurement of premorbid adjustment in chronic schizophrenia. Schizophr Bull 1982, 8:470-484.

45. Smith N, Lam D, Bifulco A, Chekley S: Childhood Experience of Care and Abuse Questionnaire (CECA.Q). Validation of a screening instrument for childhood adversity in clinical populations. Soc Psychiatry Psychiatr Epidemiol 2002, 37:572-579.

46. Bernstein DP, Ahluvalia T, Pogge D, Handelsman L: Validity of the childhood trauma questionnaire in an adolescent psychiatric population. J Am Acad Child Adolesc Psychiatry 1997, 36:340-348.

47. Olweus D: Bullying at School: What We Know and What We Can Do. Cambridge: Blackwell Publishers; 1993.

48. Mollica RF, Caspi-Yavin Y, Bollini P, Truong T, Tor S, Lavelle J: The Harvard Trauma Questionnaire. Validating a cross-cultural instrument for measuring torture, trauma, and posttraumatic stress disorder in Indochinese refugees. J Nerv Ment Dis 1992, 180:111-116.

49. Araya R, Montgomery A, Rojas G, Fritsch R, Solis J, Signorelli A, Lewis G Common mental disorders and the built environment in Santiago, Chile. Br J Psychiatry 2007, 190:394-401.

50. Williams DR, Yan Y, Jackson JS, Anderson NB: Racial differences in physical and mental health: socio-economic status, stress and discrimination. J Health Psychol 1997, 2:335-351. 
51. Stirling J, Barkus EJ, Nabosi L, Irshad S, Roemer G, Schreudergoidheijt B, Lewis S: Cannabis-induced psychotic-like experiences are predicted by high schizotypy. Confirmation of preliminary results in a large cohort. Psychopathology 2008, 41:371-378.

52. Fowler D, Freeman $D$, Smith B, Kuipers E, Bebbington $P$, Bashforth $H$, Coker S, Hodgekins J, Gracie A, Dunn G, Garety P: The Brief Core Schema Scales (BCSS): psychometric properties and associations with paranoia and grandiosity in non-clinical and psychosis samples. Psychol Med 2006, 36:749-759.

53. Konings M, Bak M, Hanssen M, Van Os J, Krabbendam L: Validity and reliability of the CAPE: a self-report instrument for the measurement of psychotic experiences in the general population. Acta Psychiatr Scand 2006, 114:55-61.

54. Struening EL, Perlick DA, Link BG, Hellman F, Herman D, Sirey JA: Stigma as a barrier to recovery: the extent to which caregivers believe most people devalue consumers and their families. Psychiatr Serv 2001, 52:1633-1638.

55. World Health Organization - Division of Mental Health (WHO): Schedule for Clinical Assessment in Neuropsychiatry, Version 2.1. Geneva: Present state examination; 1998

56. Kirkpatrick B, Buchanan RW, McKenney PD, Alphs LD, Carpenter WT Jr: The Schedule for the Deficit syndrome: an instrument for research in schizophrenia. Psychiatry Res 1989, 30:119-123.

doi:10.1186/1471-244X-14-186

Cite this article as: Tarricone et al:: First-episode psychosis and migration in Italy (PEP-Ita migration): a study in the Italian mental health services. BMC Psychiatry 2014 14:186.

\section{Submit your next manuscript to BioMed Central and take full advantage of:}

- Convenient online submission

- Thorough peer review

- No space constraints or color figure charges

- Immediate publication on acceptance

- Inclusion in PubMed, CAS, Scopus and Google Scholar

- Research which is freely available for redistribution 